\title{
Conflicto político y diseños institucionales de participación en el caso chileno*
}

\author{
Gonzalo Delamaza**
}

\begin{abstract}
Resumen
La escasa involucración de los ciudadanos, el debilitamiento de los mecanismos de representación, la tecnificación del proceso de toma de decisiones, y el predominio de las concepciones elitistas y solo delegativas en América Latina, son factores que han llevado a plantear la necesidad de fortalecer la "dimensión participativa de la democracia" (O'Donnell, 1993; Avritzer, 2002; PNUD, 2004). En Chile el tema ha suscitado relativo entusiasmo pero ha tenido escasos frutos, generándose diversas iniciativas legales y de política pública para abordarlo. Sin embargo, el diseño de la gobernabilidad democrática hegemónico desde fines de los ochenta ha restringido la participación institucional a instancias de escaso poder, de carácter principalmente consultivas y no vinculadas a la creación de espacio público deliberativo. La posibilidad de ampliación de dicha participación supone hacer coherentes los esfuerzos hasta ahora aislados y carentes tanto de una voluntad política clara, como de estándares que garanticen su sostenibilidad e institucionalización.
\end{abstract}

Palabras clave: Participación ciudadana - políticas públicas - mecanismos de participación - democracia.

\begin{abstract}
There are many reasons that highlight the need to foster "participative dimension of democracy". Some of them are the lack of enough involvement of citizens, the weakening of the traditional ways of representation, the increasingly technocratic character of the decision making process and the predominance of the elitist and delegative conception of democracy in Latin America (O'Donnell, 1993; Avritzer, 2002; PNUD, 2004). In Chile there has raised an enthusiastic debate but with lack of outcomes, despite the variety of legal initiatives and public policies to deal with this issue. But the democratic governance design that has been hegemonic since late eighties has restricted institutional participation to powerless mechanisms, with a mainly consultative character and not linked to the creation of a deliberative public space. The possibility of broadening of such participation needs to align the different efforts. Until now they have been isolated and lacking of a clear political will, just as of standards that could assure their sustainability and institutionalization.
\end{abstract}

Keywords: Citizen participation - public policies - participation mechanisms - democracy.

* Este artículo forma parte del proyecto FONDECYT № 1085180 Agendas de participación ciudadana y redes de política pública como componentes de la reforma democrática del Estado, dirigido por el autor.

** Sociólogo por la Universidad Católica de Chile y Diplomado (D.E.A.) por la Escuela de Altos Estudios en Ciencias Sociales, París. Estudios de doctorado en la Universidad de Leiden, Holanda. Ha sido profesor visitante en el Centro de Estudios Latinoamericanos de Harvard University. Investigador de la Universidad de Los Lagos en Santiago, donde dirige el Programa Ciudadanía y Gestión Pública. 


\section{EL DEBATE SOBRE PARTICIPACIÓN CIUDADANA, ¿TODOS DE ACUERDO?}

Durante los años noventa la participación ciudadana pareció ser una idea políticamente correcta, es decir, formó parte del discurso oficialmente aceptado. Pero su significado permaneció en la ambigüedad y su despliegue fue muy acotado. En cualquier caso, hablar de participación ciudadana en el contexto de los noventa no comprometía ningún cambio concreto en las orientaciones y prácticas del proceso político e institucional (Delamaza, 2005; Más Voces, 2005). La situación cambió el 2006, con la apertura -y rápida clausuradel debate sobre "gobierno ciudadano", realizado con una amplia e intensa aunque breve movilización social -la rebelión de los pingüinos-como telón de fondo ${ }^{1}$. Ese debate permitió ver que el consenso no era tal, cuando se trataba de poner en práctica transformaciones concretas en el modo de gobernar (Delamaza, 2006). Surgieron así voces explícitamente contrarias a la introducción de nuevos mecanismos de participación institucional, y que denunciaron la idea de "gobierno ciudadano" como algo carente de sentido y preñado de peligros. Las principales vertientes de crítica pueden sistematizarse en tres: a) las limitaciones propias de los espacios de participación. Se cuestiona la formación de "elites participativas" en el nivel, las que hacen predominar finalmente los intereses de los grupos organizados por sobre los no organizados, y por tanto situaciones de "captura de los espacios públicos"; b) las exigencias de racionalidad de las políticas públicas, frente a la "racionalidad limitada" de la ciudadanía. Se cuestiona la falta de conocimiento técnico de los ciudadanos/as, la dispersión de sus demandas, las dificultades de gestión, y la pérdida de eficiencia y mayor gasto de recursos en la obtención de soluciones, y c) el debilitamiento de la democracia representativa. Se cuestiona el que la participación ciudadana directa pueda provocar un proceso de informalización de la política, al establecer canales alternos no institucionalizados de mediación, con el consecuente debilitamiento de los partidos políticos y conflictos con las instancias surgidas desde elecciones populares ${ }^{2}$.

Sin embargo, y más allá del debate teórico e histórico-cultural, han surgido en Chile y Latinoamérica, una multitud de experiencias que permiten realizar también un debate empírico sobre las formas de democracia directa y de democracia participativa y sus instrumentos de gestión, muy vinculados por cierto a modificaciones y nuevos enfoques de políticas públicas. Entre estas experiencias podemos contar: el reconocimiento constitucional a los mecanismos de democracia directa (iniciativa popular de ley, revocatoria de mandato y plebiscitos); diversas reformas legales y administrativas; diseños de política y de programas (PNUD, 2004; Payne, 2003; Hevia, 2005; Delamaza, 2009); en el ámbito local destacan los presupuestos municipales participativos; Consejos Gestores; Mesas de Concertación; órganos de contraloría social; e instrumentos y normativas de planificación participativa (Montecinos, 2007; Grompone, 2007; Bebbington et al., 2005). En este artículo no abordaremos lo

1 Al inicio de su gobierno, la presidenta Michelle Bachelet (2006-2010) indicó que quería modificar su modo de ejercer el poder por medio de lo que llamó "gobierno ciudadano". A menos de un mes de asumido el gobierno, se produjo la primera movilización social masiva y en la calle desde 1989. Fue protagonizada durante algunas semanas por los estudiantes de enseñanza media y se la llamó "rebelión de los pingüinos", por la apariencia que presentan los estudiantes vestidos de uniforme, reunidos en grandes grupos.

2 Ver, entre otros, los siguientes trabajos: Canto (2005), Bebbington et al. (2005) y Boeninger (2007). 
referido a las necesarias reformas del sistema político, sino sólo aquello referido al diseño, implementación y evaluación de políticas públicas.

El Estado no tiene una posición homogénea frente al tema de la participación. Diferentes "capas geológicas" del Estado y centros de iniciativa política pertenecientes a él expresan distintas orientaciones, programas, objetivos y estrategias, que muchas veces se contraponen entre sí (Delamaza, 2005). En el Ejecutivo chileno, por ejemplo, se pueden diferenciar los núcleos estratégicos (Presidencia, Interior y Hacienda), de los de la sectorialidad social tradicional (ministerios sociales) y los programas innovadores (MIDEPLAN principalmente), que no mantienen iniciativas coherentes entre sí. Tampoco se da una situación articulada entre los niveles de la institucionalidad, siendo especialmente débil el nivel regional (no cuenta con estructuras de participación) y con un diseño muy limitado el ámbito municipal, como lo muestran las escasas evaluaciones al respecto (SUBDERE, 2004; Más Voces, 2005). De allí las dificultades para impulsar iniciativas explícitas de reforma en esta materia, que han surgido desde el propio Ejecutivo a partir del año $2000^{3}$.

Incluso las políticas de modernización del Estado aplicadas en Chile resultan poco claras al respecto, pues si bien sus objetivos centrales fueron desde el inicio "hacer más eficientes los servicios públicos y fortalecer la democracia por medio de una gestión pública participativa" (Comité de Modernización, 2000: 16), en la práctica, el énfasis ha sido dado a la eficiencia y no a la participación, asumiendo la modernización del Estado un enfoque "gerencialista", a la par de los altos rangos de discrecionalidad y de autonomía que han ganado sus elites tecno-burocráticas ${ }^{4}$. Esta situación recién comienza a cambiar, y a girar hacia la participación, aunque en forma muy paulatina y con alcances aún incipientes, a partir del año 2002 (Montecinos, 2007: 329). Sin embargo, no se aprecia una estrategia integrada de reforma estatal que incorpore el componente de participación. Al interior de la institucionalidad estatal se pueden identificar diferentes enfoques y tensiones, que han tenido consecuencias sobre las iniciativas en pro de la participación, sus avances y retrocesos ${ }^{5}$.

La tradición histórica chilena, su cultura política y sus prácticas estatales tampoco ofrecen modelos útiles a los desafíos actuales de la participación ciudadana. El Estado unitario, centralizado y dividido sectorialmente, el sistema político presidencialista (reforzado por el binominalismo), junto al impacto de las reformas institucionales neoliberales (muchas de las cuales no han sido modificadas con posterioridad a 1990), crean condiciones desfavorables para la participación. La tradición de "iluminismo democrático" del Estado chileno hace

3 Desde el año 2004 se tramita en el Parlamento una Ley de Asociatividad y Participación de la Sociedad Civil en la Gestión Pública, sin que hasta la fecha de elaboración de este artículo (marzo 2010) se haya aprobado.

Sobre tecnocracia y política, ver Silva (2006) y BID (2006).

En octubre de 2009, el Consorcio para la Reforma del Estado, compuesto por siete think tanks, expresivos del arco político de la Concertación y la oposición de derecha, junto a cuatro centros universitarios, dieron a conocer una propuesta transversal sobre reforma del Estado. En ella el tema de participación ocupa cuatro numerales (sobre un total de 109 en el total del documento). Uno afirma la necesidad de un enfoque amplio; el segundo alerta sobre los "costos y riesgos de intervención y captura por grupos de interés particulares"; el tercero propone difundir "documentos de consulta de medidas de política" para recibir aportes; y el cuarto remite a la necesidad de descentralizar el Estado (Consorcio para la Reforma del Estado, 2009: 21-22). 
que privilegie el cambio y las reformas "desde arriba" y con "sentido nacional", antes que aquellas dirigidas "desde abajo" y que contengan algún tipo de "ethos local" (Salazar y Pinto, 2000).

Los diversos trabajos que sistematizan la experiencia latinoamericana arrojan varias conclusiones en común. En general, coinciden en señalar que el éxito en la transformación de los métodos y los objetivos de gestión de las políticas públicas no dependen de la mera existencia de mecanismos participativos, sino que fundamentalmente de la capacidad existente en las contrapartes de la sociedad civil para hacerlos exigibles. Lo mismo ocurre del lado del sector público, pues el éxito de la nueva gestión pública participativa dependería fundamentalmente de la capacidad de los funcionarios públicos de aprehender y de generar compromisos con estos nuevos enfoques. Vale decir, que la mera promulgación legal o instalación administrativa de la democracia participativa no resulta en sí misma suficiente ${ }^{6}$.

En este artículo se proponen categorías conceptuales para clasificar y analizar las características y el potencial democratizador de los diferentes mecanismos de participación que se han ensayado en diversos contextos. Luego se traza la trayectoria política de la participación institucional en el país y se releva la evidencia empírica con que se cuenta respecto de lo realizado en distintos ámbitos de política. La hipótesis del trabajo es que la concepción de participación dominante en las políticas públicas -consistente con el diseño de la gobernabilidad democrática hegemónico desde fines de los ochenta- ha restringido la participación institucional a instancias de escaso poder, de carácter principalmente consultivas y no vinculadas a la creación de espacio público deliberativo. En el acápite final se proponen algunas de las innovaciones institucionales y conceptuales que debieran producirse para hacer de la participación ciudadana un real factor de profundización democrática.

\section{CATEGORÍAS DE PARTICIPACIÓN CIUDADANA: ¿PARA QUÉ?, ¿POR QUÉ?, ¿CUÁNDO? Y iCÓMO?}

No toda participación se ejerce por la vía institucional, ni tampoco toda participación incidente en las políticas y la gestión pública se realiza por vías institucionales. De hecho, la relevancia de las vías institucionales tiene relación con su capacidad de canalizar efectivamente las demandas existentes en la sociedad, reduciendo los costos de transacción implicados y con una expectativa razonable de obtener resultados positivos. En la relación entre el Estado y la sociedad en América Latina esos elementos no han estado tradicionalmente presentes, predominando relaciones de cooptación e incorporación subordinada (populismo, clientelismo, caudillismo) o la confrontación, sea por la vía de formas más o menos violentas o por la vía de los movimientos sociales y de protesta organizada que realizan presión por obtener sus demandas, buscando impactar las políticas por fuera de la institucionalidad (BID, 2006).

\footnotetext{
6 Ver al respecto los trabajos de Bebbington et al. (2005), Canto et al. (2003). También: López y Pacheco (2006), Márquez et al. (2001) y Remy (2005).
} 
Un intento por clasificar las formas de participación según su relación con la institucionalidad y su capacidad de incidir es el propuesto por María Isabel Remy. El caso peruano, analizado por la autora, muestra que la efectividad política de los mecanismos no institucionalizados, particularmente la protesta pública, resulta mayor que la que se obtiene a través de los mecanismos institucionalizados, en especial los de "diálogo con la autoridad". Estos últimos, aunque establecidos por la ley y formalmente operativos, no resultan eficaces para abordar materias significativas, ni cuentan con gran legitimidad entre la población peruana (Remy, 2005). De tal manera que el desafío no consiste solamente en institucionalizar, sino dotar a este nuevo tipo de instituciones de atribuciones y consecuencias prácticas que las hagan relevantes a los ojos de la población y los ciudadanos.

También se puede mirar la participación desde el punto de vista de quiénes, cómo y para qué se involucran. Este punto de vista permite una apreciación de los mecanismos institucionales y operativos que existen en el proceso, más allá del nivel de decisión que las personas puedan alcanzar. Los tipos de participación son clasificados en asociativos y personales. En los primeros la participación se realiza en nombre de organizaciones o asociaciones, mientras que en los segundos se participa de manera individual, en tanto ciudadano/a individual. A su vez la participación asociativa puede ser relativa a temas sectoriales, o bien ejercerse en el plano territorial. Y la personal puede ser intensiva, es decir, que requiere de mayor dedicación de tiempo y recursos, así como un proceso de acciones sucesivas a realizar (como ocurre con el presupuesto participativo y con la participación en las instancias contempladas en el Sistema de Evaluación de Impacto Ambiental, por ejemplo), o bien extensiva, que alcanza a muchas personas, pero a través de actos simples y fáciles de realizar (como una consulta electrónica o una encuesta de satisfacción de usuario). Las formas intensivas son mejores para deliberar pero involucran a un activo más pequeño de personas, normalmente líderes. Las extensivas no permiten la deliberación, pero ayudan a tomar decisiones con mayor legitimidad y pueden involucrar grandes cantidades de personas (Font et al., 2000).

Otro punto de vista es mirar la participación según los niveles que alcanza en cada una de las fases de la política. En un trabajo reciente, Fernández y Ordóñez revisan las distintas categorías utilizadas y proponen una clasificación que evite algunas duplicaciones e inconsistencias de las clasificaciones anteriores. Las etapas o fases de la política se clasifican en información, diagnóstico y decisión, implementación y evaluación y reformulación. Estas se cruzan con los niveles que puede alcanzar la participación y su impacto concreto en la ciudadanía. La escala aquí va desde la no participación (pero que muchas veces es presentada como tal) hasta la participación empoderadora, pasando por las modalidades instrumentales (Fernández y Ordóñez, 2007).

En el caso de la participación empoderadora, resulta deseable describir el tipo de poder que otorga a la ciudadanía, es decir, poder ipara qué? Desde el punto de vista de la gestión pública, que estamos analizando prioritariamente aquí, el poder se puede clasificar en diferentes categorías: poder de denuncia, de certificación, de asignación, de deliberación y de escrutinio (Cunill, 2007). Estas categorías permiten una mayor precisión al momento de 


\section{CUADRO 1}

Matriz de clasificación de la participación ciudadana.

Tipos de participación y fase asociada de la política

\begin{tabular}{|c|c|c|c|c|c|}
\hline \multicolumn{2}{|c|}{ NO PARTICIPACIÓN } & \multicolumn{3}{|c|}{ TIPO DE PARTICIPACIÓN } & \multirow{2}{*}{$\frac{\text { FASE ASOCIADA }}{\text { Información }}$} \\
\hline \multirow[t]{2}{*}{ Uso de TI } & \multirow[t]{2}{*}{ Campañas } & \multirow{2}{*}{$\begin{array}{c}\text { Difusión de } \\
\text { información }\end{array}$} & & & \\
\hline & & & $\begin{array}{c}\text { Consulta } \\
\text { vinculante }\end{array}$ & $\begin{array}{l}\text { Participación } \\
\text { deliberativa }\end{array}$ & $\begin{array}{l}\text { Diagnóstico y } \\
\text { decisión }\end{array}$ \\
\hline \multirow{2}{*}{\multicolumn{2}{|c|}{$\begin{array}{l}\text { Gestión interna, mejora } \\
\text { de atención al usuario }\end{array}$}} & Ejecución delegada & \multicolumn{2}{|c|}{ Coejecución, supervición } & Implementación \\
\hline & & $\begin{array}{c}\text { Evaluación pasiva: } \\
\text { consulta, quejas } \\
\text { y reclamos }\end{array}$ & \multicolumn{2}{|c|}{$\begin{array}{l}\text { Reformulación deliberativa } \\
\text { (Control social) }\end{array}$} & $\begin{array}{l}\text { Evaluación y } \\
\text { reformulación }\end{array}$ \\
\hline
\end{tabular}

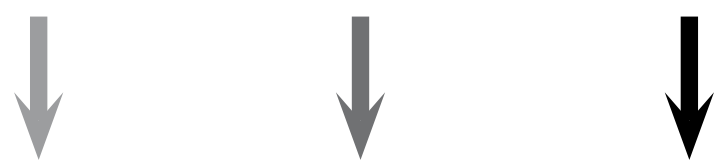

\begin{tabular}{|c|c|c|}
\hline $\begin{array}{c}\text { NO PARTICIPACIÓN } \\
\text { ENCUBIERTA }\end{array}$ & $\begin{array}{c}\text { PARTICIPACIÓN } \\
\text { INSTRUMENTAL }\end{array}$ & $\begin{array}{c}\text { PARTICIPACIÓN } \\
\text { EMPODERADORA }\end{array}$ \\
\hline
\end{tabular}

Fuente: Fernández y Ordóñez (2007: 33).

planificar o de evaluar los mecanismos de participación concretos y los espacios que abren a la ciudadanía participante.

Por último, veremos que los distintos mecanismos de participación tienen diferentes ventajas y desventajas, las que son importantes de considerar a la hora de promoverlos. De tal manera que se requerirá un diagnóstico de la situación en la que se quiere poner en práctica el proceso, así como los objetivos prioritarios que se persiguen con la participación, los que difieren según casos y lugares. De esta manera podemos proponer una última forma de clasificar la participación ciudadana, esta vez según diferentes criterios, que nos permitirá evaluar potencialidades y limitaciones de acuerdo a los objetivos perseguidos.

\section{LA PARTICIPACIÓN EN CHILE: POLÍTICAS PÚBLICAS}

Se ha afirmado precedentemente que los avances en la materia en el país son aún escasos y acusan múltiples deficiencias, existiendo un amplio campo de avance posible para los efectos de contar con una gestión pública participativa, con mayores grados de involucramiento de la ciudadanía y con una mayor eficiencia y eficacia en la gestión. En 


\section{CUADRO 2}

Clasificación de instrumentos de participación según características relevantes

\begin{tabular}{|l|l|l|}
\hline \multicolumn{1}{|c|}{ CRITERIOS } & \multicolumn{1}{|c|}{ ACONSEJABLE } & \multicolumn{1}{c|}{ DEFICITARIO } \\
\hline Representatividad & Encuesta deliberativa & Consejo consultivo \\
\hline Grado de información/deliberación & Consejo consultivo & $\begin{array}{l}\text { Plebiscito } \\
\text { Encuestas }\end{array}$ \\
\hline Capacidad educativa & $\begin{array}{l}\text { Presupuesto participativo } \\
\text { Planes estratégicos }\end{array}$ & Consejo consultivo \\
\hline Extensión & $\begin{array}{l}\text { Plebiscito } \\
\text { Presupuesto participativo }\end{array}$ & Consejo consultivo \\
\hline Costo/dificultad organizativa & Consejo consultivo & $\begin{array}{l}\text { Encuesta deliberativa } \\
\text { Presupuesto participativo }\end{array}$ \\
\hline Impacto en políticas & $\begin{array}{l}\text { Plebiscito } \\
\text { Presupuesto participativo }\end{array}$ & Encuesta deliberativa \\
\hline
\end{tabular}

Fuente: Font (2004).

este apartado examinamos algunos de los datos que existen sobre este tema, considerando, sin embargo, que los estudios empíricos son escasos en nuestro país en comparación con otros países de América Latina. La agenda de participación está relativamente ausente de la investigación académica en Chile y no existen centros especializados en esta materia ${ }^{7}$.

\subsection{La participación ciudadana realmente existente}

Durante los dos primeros gobiernos de la Concertación (1990-2000) el estímulo de la participación se hizo principalmente dentro de los diseños de los programas sociales. Para ello se buscó incorporar a los organismos no gubernamentales, así como a las organizaciones de base, dentro de distintas fases de ejecución de los programas, con énfasis en el cofinanciamiento y la implementación. El principal programa de la época fue el de "pavimentos participativos", mediante el cual los ciudadanos de comunidades pobres cofinanciaban la pavimentación de sus calles y pasajes, subsidiando así al Estado, cuyos

7 Un relevamiento del conocimiento producido a través de encuestas sobre este tema en el país, desde 1990 hasta el 2006, indica que sólo se cuenta con series de datos sobre la participación electoral y la participación en organizaciones (en términos cuantitativos), mientras que la gran cantidad de estudios de opinión no incorporan esta temática en sus preguntas (Gerber, 2007). 
recursos resultaban insuficientes ${ }^{8}$. El problema de la participación ingresó como tal a la agenda política en la campaña presidencial de 1999, recién después que se produjeron cambios en el cuadro político electoral a fines de 1997.

A fines de 1997 se realizaron en Chile elecciones parlamentarias en las cuales la coalición gobernante perdió alrededor de un millón de votos. Gran parte de esos votantes optó por no concurrir a votar o anular su voto en la urna, normalmente con consignas antipolíticas o simplemente expresiones de descontento. Al año siguiente el crecimiento económico disminuyó sensiblemente acusando los efectos de la llamada "crisis asiática", lo que impactó sobre el empleo y en general las expectativas de la población. Ambos hechos -la desafección política y el relativo agotamiento del modelo de crecimiento vigente desde mediados de los ochenta- marcaron un cambio de etapa en el rumbo político de la transición chilena ${ }^{9}$. Por ello no es de extrañar que los siete candidatos a la presidencia en 1999 lo hicieran en nombre de la necesidad de introducir cambios significativos en la conducción del país, contrastando con el claro sesgo continuista de la anterior elección realizada en 1993.

Ricardo Lagos, el candidato de la coalición de gobierno, que resultó ganador por estrecho margen, levantó la oferta de fortalecer la función pública en materias de protección social, expresadas en una reforma del sistema de salud. También abordó el tema de la participación ciudadana y la necesidad de fortalecimiento de la sociedad civil, así como de profundizar la reforma del Estado. Se convocó a un Consejo Ciudadano de amplia composición para formular una política de fortalecimiento de la sociedad civil, lo que abrió expectativas de cambio en ese plano (DOS, 2007). La mayor prioridad política que había adquirido el tema de la participación ciudadana se expresó en la promulgación de un plan gubernamental que recogió los planteamientos del Consejo Ciudadano ${ }^{10}$. En el 2002 se dictó un Instructivo Presidencial de Participación Ciudadana que llevó a que los diferentes ministerios comprometieran metas específicas apuntando a incorporar la participación en las políticas y programas que impulsan. El 2004 se presentó al Parlamento el proyecto de ley sobre Asociatividad y Participación Ciudadana en la Gestión Pública.

Una evaluación de la incorporación de la participación ciudadana en las políticas y programas públicos realizada el 2007, a partir del Informe Gubernamental realizado por la División de Organizaciones Sociales (DOS, 2007), arroja la sorprendente cantidad de 305 mecanismos de participación, correspondientes a 155 compromisos de participación ciudadana establecidos por la totalidad de los 18 ministerios en que se divide la administración

8 El Informe sobre el Programa de Pavimentación Participativa comienza así: "El Programa de Pavimentación Participativa es una iniciativa del gobierno nacional comenzada en 1995, que sustituyó un programa anterior de "Pavimentos Participativos" del Ministerio de Vivienda y Urbanismo (Minvu) que, a pesar de su nombre, no consideraba la participación de los vecinos" (Valenzuela et al., 2000: 158).

9 Adicionalmente, aconteció que, en octubre de 1998, el general Pinochet fue detenido en Londres lo que lo obligó en definitiva a retirarse de la escena política a su regreso en abril de 2000. Ello marcó también un cambio relevante en la agenda política del país, alejando los temores de una mayor influencia militar en ella.

10 El Consejo fue formado por 28 ciudadanos/as vinculados a distintas organizaciones y cuatro representantes ministeriales. Ver el texto de la respuesta presidencial al Informe del Consejo en: http://www.portalciudadano. cl/detalle_noticia.html?id=69;id_seccion=129. 
central (Fernández y Ordóñez, 2007: 32). Sin embargo, la misma evaluación muestra el escaso potencial efectivo de promoción de la participación ciudadana.

El análisis de la iniciativa gubernamental entrega datos que confirman, seis años después de establecido el instructivo presidencial, la falta de avances sustantivos en la materia. Por un lado se establece que un $37 \%$ de lo que se informa como participación por parte de los ministerios y servicios -y se publica como tal por la DOS- no corresponde a participación. Ello evidencia una falta de comprensión y claridad, así como ausencia total de estándares, respecto de la materia en cuestión. Los instrumentos participativos puestos en práctica están concentrados en la modalidad instrumental (44\%), muy principalmente en la modalidad más básica de esta: la participación informativa, que alcanza un $26 \%$ del total de mecanismos. La participación que los autores Ilaman "empoderadora", pues tiene consecuencias de fortalecimiento tanto para la gestión estatal como para los participantes de la sociedad civil sólo alcanza un 19\% (Fernández y Ordóñez, 2007). Dichas iniciativas no han comprometido ningún reacomodo institucional, siguiendo en este sentido la tendencia previa: fortalecer programáticamente las instancias existentes, sin enfrentar los desafíos de cambio institucional ni de rediseño político que introducir la participación supone.

Estos resultados muestran la falta de un concepto claro acerca de lo que la participación puede significar para las políticas públicas. No solamente los ministerios y servicios informan erróneamente a la repartición encargada del seguimiento (la DOS), sino que ésta carece de

\section{CUADRO 3}

Mecanismos de participación incorporados a la gestión pública según tipos de participación

\begin{tabular}{|c|c|c|c|}
\hline \multirow{2}{*}{\multicolumn{2}{|c|}{ NO PARTICIPACIÓN }} & \multicolumn{2}{|c|}{ TIPO DE PARTICIPACIÓN } \\
\hline & & INSTRUMENTAL & EMPODERADORA \\
\hline \multirow[t]{2}{*}{$\begin{array}{l}\text { Uso de tecnologías de } \\
\text { información 3,3\% }\end{array}$} & Campañas 9,2\% & $\begin{array}{l}\text { Difusión de la información } \\
26,2 \%\end{array}$ & \\
\hline & & $\begin{array}{l}\text { Consulta no vinculante } \\
8,9 \%\end{array}$ & $\begin{array}{l}\text { Participación } \\
\text { deliberativa 9,8\% }\end{array}$ \\
\hline \multirow{2}{*}{\multicolumn{2}{|c|}{$\begin{array}{l}\text { Gestión interna, mejora de atención al } \\
\text { usuario } 24,9 \%\end{array}$}} & Ejecución delegada 3,0\% & $\begin{array}{l}\text { Coejecución, } \\
\text { supervisión 5,9\% }\end{array}$ \\
\hline & & $\begin{array}{l}\text { Evaluación pasiva: } \\
\text { consultas, quejas, } \\
\text { reclamos 5,6\% }\end{array}$ & $\begin{array}{l}\text { Reformulación } \\
\text { deliberativa (control } \\
\text { social) } 3,3 \%\end{array}$ \\
\hline
\end{tabular}

$\mathrm{N}=305$ (mecanismos institucionalizados de participación informados en DOS, 2007).

Fuente: Fernández y Ordóñez (2007: 47). 
estándares apropiados para orientarlos y producir el avance que se busca en la gestión del Estado. En agosto del 2008 se publicó un nuevo Instructivo Presidencial de Participación Ciudadana, referido a cuatro mandatos válidos para todos los ministerios: establecer una normativa general sobre participación ciudadana; rendir una cuenta anual de gestión y ejecución presupuestaria; diseñar mecanismos para establecer Consejos Consultivos de la Sociedad Civil y poner a disposición de la ciudadanía sus planes, programa y proyectos.

Similares problemas ha sufrido la principal iniciativa legislativa que se ha intentado durante el período: el proyecto de ley sobre Asociaciones y Participación Ciudadana en la Gestión Pública, presentado al Parlamento en junio del 2004, luego de un proceso de discusión prelegislativo de más de 3 años ${ }^{11}$. El proyecto de ley tuvo una etapa de discusión hasta el primer semestre del 2006, cuando el Ejecutivo -bajo nueva administración- envió un veto sustitutivo que reforzó sus contenidos incluyendo los siguientes aspectos principales: establece el derecho a la participación ciudadana en la gestión pública como componente de la Ley de Bases de la Administración Pública; establece la obligatoriedad de conformar Consejos de Organizaciones de la Sociedad Civil, de carácter consultivo en materias predeterminadas, en las distintas reparticiones públicas, incluyendo ministerios, servicios y municipios; establece una categoría de Asociaciones y Organizaciones de Interés Público (OIP); simplifica el trámite para constituir organizaciones de interés público, a través del sistema de registro; crea un Fondo para el Fortalecimiento de las OIP, coadministrado con representantes de estas organizaciones; establece un Estatuto del Voluntariado y establece un sistema de Cuentas Públicas que incluye la respuesta obligatoria de la autoridad a los planteamientos de la ciudadanía $^{12}$. El proyecto en cuestión fue aprobado con apoyo transversal por la Cámara de Diputados y por la Comisión de Gobierno Interior del Senado. Sin embargo, en sesión de diciembre del 2008 la Sala del Senado lo rechazó debiendo constituirse una Comisión Mixta (diputados y senadores) que deberá proponer un nuevo proyecto.

Todas las propuestas relativas a mecanismos de democracia directa, incluidas en las primeras versiones del proyecto, fueron excluidas en el enviado al Parlamento, aparentemente por acuerdos tomados entre los responsables políticos de la Concertación ${ }^{13}$. Con posterioridad, sin embargo, se envió al Parlamento una propuesta de reforma constitucional que, de aprobarse, permitiría formular luego una propuesta para establecer la iniciativa popular de ley ${ }^{14}$.

En el ámbito político a comienzos del gobierno de Bachelet (2006-2010) el debate estuvo marcado por la propuesta genérica de realizar un "gobierno ciudadano", lo que fue interpretado por actores políticos como un by pass a los partidos políticos en diversas materias de gobierno. A ello se sumó la conformación de diversos consejos y comisiones

11 El texto del proyecto de ley de 2004 en: http://www.chilevoluntario.cl/temas/ley.html.

12 Comentarios críticos sobre diversos aspectos incluidos en el proyecto de ley de Asociaciones y Participación Ciudadana en la Gestión Pública en: http://www.accionag.cl/ley.php.

13 A pesar de que el apoyo ciudadano a introducir mecanismos de democracia directa, como la revocatoria de mandato, el plebiscito y la iniciativa popular de ley bordean el 80\% (Recabarren y Aubry, 2005: 79).

14 Más antecedentes sobre este y otros proyectos anteriores sobre el tema (presentados por parlamentarios) en: http://www.iurisprudentia.cl/2008/03/24/notas-sobre-la-iniciativa-ciudadana-de-ley-ii/. 
que combinaban expertos y representantes de diversos organismos sociales, convocados para sugerir políticas de alto consenso en materias sensibles (infancia, previsión, educación). Sin embargo, lo que dio vigencia y polémica al debate sobre "gobierno ciudadano" fue la amplia movilización de los estudiantes secundarios que el gobierno debió enfrentar recién comenzando (mayo-junio de 2006). En dicho contexto se reavivó en la elite política chilena el temor al "desborde" de las demandas sociales, que había acompañado los primeros años de la transición política. Algunos sectores del propio gobierno consideraron también que la movilización estudiantil había sido estimulada por este tipo de enfoques de política. Como resultado de ello se dejó de mencionar dicha consigna.

No obstante, la iniciativa gubernamental aparece tensionada por diferentes orientaciones. Así, en septiembre del 2006 la presidenta presentó los contenidos de su Agenda Pro Participación. Se aprecia una clara diferencia entre el fundamento que la presidenta esgrime en su discurso y el contenido concreto de la Agenda, lo que probablemente exprese las tensiones entre la voluntad programática y las restricciones políticas. El primero incluye reformas políticas: sistema binominal, inscripción automática, participación política de la mujer, voto de chilenos en el exterior; elección de autoridades regionales; reforma municipal para crear gobiernos locales; iniciativa popular de ley; entre otras. La agenda específica, en cambio, resulta mucho más limitada. En ella se propone la formación de consejos de organizaciones de la sociedad civil, con carácter consultivo, en diferentes niveles; el incremento del fondo concursable para apoyo de las organizaciones sociales; proyectos de infraestructura regional para albergar organizaciones; mejorar el acceso a la información sobre políticas públicas y el impulso de las medidas contra la discriminación y en pro de la tolerancia ${ }^{15}$.

\subsection{Diversidad de modalidades consultivas en la institucionalidad participativa}

Otro aspecto relevante de considerar es la variedad de mecanismos institucionales que se han instalado desde 1990 en adelante, bajo la forma de "consejos", la mayoría de ellos de carácter consultivo, donde concurre el sector público y la sociedad civil. La mayor parte de ellos se conforma a través de lo que María Isabel Remy Ilama participación "por invitación", que busca incorporar visiones externas al Estado, seleccionando integrantes de manera unilateral por parte de la autoridad, sin arreglo a estándares, sino a razones de estrategia política (Remy, 2005). Esto ha dado un predominio amplísimo a técnicos y profesionales especializados, así como a la reiteración de un esquema que reúne a técnicos cercanos a la Concertación y a la oposición de derecha, quienes normalmente concuerdan aspectos que luego, eventualmente, serán materia de proyectos gubernativos. Este esquema se volvería a repetir en el caso de las Comisiones Asesoras Presidenciales organizadas por el gobierno de Bachelet (Aguilera, 2009). Una revisión de los estatutos y características de dichos Consejos revela una gran variedad de criterios para su conformación, así como en el alcance y atribuciones que se les entregan. Sin embargo, la misma variedad existente,

15 Ver los contenidos principales del discurso y la agenda en: http://www.prensapresidencia.cl/view/viewFrameComunicado.asp?codigo $=5262$. 
indica que se trata de un mecanismo ampliamente utilizado, que cumple una función en la legitimación política de los gobiernos de la Concertación, por lo que vale la pena intentar una clasificación.

En primer término están los Consejos Directivos conformados a través de mecanismos de cooptación selectiva. A través de diversos criterios se incluyen personas designadas por el Presidente/a de la República provenientes de distintos sectores. En el caso del FOSIS, este incluye representantes de diferentes ministerios y servicios públicos y cuatro personas no pertenecientes al ámbito gubernamental: del sector empresarial, sindical, académico y de organismos no gubernamentales. Sus funciones son directivas, aunque de hecho las delega en el Director Ejecutivo. También es el caso de la Comisión CONICYT integrada por diversas personas del mundo académico. Lo interesante de estos consejos es que tienen a su cargo funciones de orientación política de las reparticiones mencionadas.

Una segunda vía de constitución de los consejos, la de más reciente creación, es la designación a propuesta de organizaciones del sector involucrado, como ocurre con el Consejo Nacional de la Cultura y las Artes, donde son diversas ramas artísticas quienes proponen al presidente ternas de nombres para su selección. Este Consejo cumple de hecho la función de un ministerio, pues su presidenta tiene rango ministerial y es de confianza del presidente.

Una tercera modalidad es la que presenta la Comisión Nacional de Desarrollo Indígena (CONADI), cuyo consejo está conformado por representantes del Presidente de la República y consejeros electos periódicamente por las diferentes etnias reconocidas en el país. Los sucesivos conflictos institucionales sufridos por esa organización sugieren que dicha combinación de consejeros no ha tenido los resultados que se esperaron. Por una parte, frente a los conflictos más importantes, tanto algunos de los representantes del Presidente se han comportado autónomamente, lo que ha llevado a su remoción. Por otra, la legitimidad electoral de los consejeros indígenas se confronta con su condición minoritaria en el Consejo. Eso ha llevado en diversas ocasiones a situaciones altamente conflictivas. Ello ocurrió especialmente durante el período de Eduardo Frei, quien privilegió explícitamente la construcción de obras de infraestructura y viales por sobre la aplicación de la Ley Indígena o la oposición de sectores indígenas.

Lo más extendido son los consejos consultivos, entre los cuales se puede mencionar el de la Comisión Nacional de Medio Ambiente (CONAMA), el del Fondo de Fortalecimiento de la Sociedad Civil y los Consejos del sector salud (Consejos de Hospitales, Consejos Comunales de Salud y Consejos Integrados de la Red Asistencial (CIRA)). También el Sistema de Garantías Explícitas en Salud (Plan AUGE) cuenta con un Consejo Consultivo conformado por especialistas del área de salud.

Otras modalidades de constitución fueron las utilizadas en el caso del Fondo de las Américas, al cual concurrían representantes de diversos ministerios, un representante del gobierno de Estados Unidos (de donde provenían los recursos) junto a un número mayoritario de representantes electos de las organizaciones beneficiarias del fondo, uno de los cuales lo 
presidía. Similar es el sistema contemplado para el Consejo del Fondo de Fortalecimiento de la Sociedad Civil en el proyecto de ley sobre participación y asociatividad ${ }^{16}$. La experiencia del Consejo del Fondo de las Américas no presentó los conflictos de la CONADI, a pesar de que, al igual que este, su consejo incluía la participación directa de consejeros legitimados electoralmente. Ello lleva a pensar que los problemas no emanan necesariamente de introducir participación directa de sectores sociales, sino del marco legal y político en que estos consejos se desenvuelven.

También se han producido problemas debidos al centralismo de la gestión pública en Chile. Ha sido el caso de los conflictos ambientales, en los cuales en más de una ocasión los ministros sectoriales han impuesto sus decisiones a las Comisiones Regionales del Medio Ambiente (COREMA). La particularidad de las COREMAs, es que están reguladas por la ley de medio ambiente y cuentan con atribuciones definidas. Medio ambiente es el único sector que cuenta con una institucionalidad participativa sancionada legalmente. En este caso, las atribuciones de los organismos participativos suelen colisionar con la tradición y cultura política chilena de decidir desde el centro. Este problema no afecta solamente a los representantes de la sociedad civil, sino también a los representantes regionales del gobierno, que ven así cercenadas sus atribuciones establecidas por ley.

Finalmente, en el último tiempo se han creado Comisiones y Consejos Asesores Presidenciales de carácter transitorio, establecidos para ampliar el debate y los criterios con anterioridad a la formulación de políticas o la presentación de proyectos de ley. Dichas comisiones han sido publicitadas como un mecanismo de participación, pero manifiestan una gran diversidad de criterios en cuanto a su conformación, tendiendo en general a sobrevalorar el papel de los técnicos y especialistas sectoriales, por sobre el de la sociedad civil o las organizaciones sociales vinculadas al tema ${ }^{17}$. Pero por sobre todo la limitación de dichos consejos es su falta de articulación con las instancias de formulación y decisión de las políticas públicas, por lo cual sus resultados son extremadamente disímiles ${ }^{18}$.

De hecho la formación de consejos y comisiones ha sido un mecanismo permanentemente utilizado desde 1990, para temas de derechos humanos (Verdad y Reconciliación, Mesa de Diálogo, Comisión Valech), educación (Comisión Brunner y Comisión Asesora Presidencial de Educación), pobreza (Consejo Nacional para la Superación de la Pobreza) y pueblos indígenas (Comisión de Nuevo Trato). Más que instrumentos de participación ciudadana institucionalizada, estas comisiones pueden considerarse una respuesta ad hoc a necesidades políticas, que amplían la interlocución e intentan preparar condiciones para un acuerdo político. Por ello todas utilizan la metodología de "participación por invitación", sin establecer criterios públicos para su integración. Por eso tampoco se precisa exactamente el destino de

16 Un análisis pormenorizado de la juridicidad de estos consejos en Viveros (2008).

17 De hecho sólo el Consejo Asesor Presidencial de Educación -el más numeroso y diverso de todos- incorporó organizaciones sociales de profesores y estudiantes, quienes se retiraron antes de firmar el documento final. No ocurrió lo mismo con las referidas a Infancia, Previsión Social, Sistema Binominal y Trabajo y Equidad (Aguilera, 2009).

18 Un análisis de dichas Comisiones Asesoras bajo el gobierno de Bachelet, en Aguilera (2009). 
las propuestas que elaboran y cada una de ellas establece su modo de funcionar y la apertura de sus deliberaciones, sin que existan estándares que garanticen la participación ${ }^{19}$.

En el caso de la Comisión de Educación (2006) que privilegió la incorporación más orgánica de sectores sociales, la falta de metas claras para su trabajo y para el destino de sus propuestas, hizo que el compromiso de los sectores más críticos del gobierno fuese de corta duración y debilitó el carácter deliberativo que la instancia debía tener. Tampoco se resolvió adecuadamente la relación entre "técnicos" y "representantes". En términos de número, los primeros estaban sobrerrepresentados. Más allá de eso, las condiciones del diálogo y el destino concreto de las deliberaciones eran un asunto que no estaba resuelto con claridad. Ello condujo a que el informe de la Comisión no fuese de consenso, que luego el Ministerio de Educación filtrara las propuestas que incluiría como proyectos de ley. Finalmente se conformó otra instancia, de carácter político, donde el gobierno y los partidos que lo apoyan negociaron con la oposición el contenido concreto de las reformas.

El análisis de los Consejos Mixtos muestra que existen una gran cantidad y variedad de ellos, que se utilizan como un modo de involucrar a la sociedad civil en los asuntos públicos, lo que revela la apertura institucional para ello. Sin embargo, al no existir criterios de conformación, vínculos de tipo orgánico con las instancias sociales concernidas, ni estándares para su funcionamiento, su destino depende principalmente de variables políticas externas y su potencial disminuye.

\subsection{Los esfuerzos normativos en revisión}

El único cuerpo legal coherente de participación ciudadana en la gestión de políticas públicas es el contenido en la Ley de Bases del Medio Ambiente, referido a la participación de la comunidad en el Sistema de Evaluación de Impacto Ambiental (SEIA) al que deben someterse algunos de los proyectos de inversión en el país ${ }^{20}$. La participación ciudadana se manifiesta en diversos niveles: en primer lugar, el derecho a la información, por la obligación del proponente de publicar un extracto del proyecto o actividad sometida a una evaluación de impacto ambiental. Las organizaciones ciudadanas con personalidad jurídica y las personas naturales directamente afectadas pueden imponerse del contenido del estudio y de los documentos acompañados.

Las personas y organizaciones habilitadas pueden ejercer el derecho a opinar, mediante las observaciones fundadas que pueden hacer al proyecto o actividad, las que deben hacerse

19 Tal es la informalidad y el carácter ad hoc de estas comisiones y consejos que en el caso del Consejo Nacional para la Superación de la Pobreza, éste no sobrevivió a la desactivación del Programa Nacional del mismo nombre y se transformó en una fundación privada con financiamiento público. Tampoco tuvo continuidad alguna el nominado para analizar y proponer una reforma al sistema binominal.

20 La ley distingue entre proyectos que deben someterse a un estudio de impacto ambiental (EIA), que cuentan con una instancia de participación, de aquellos que simplemente deben entregar una declaración de impacto ambiental. En términos generales, los primeros son los más grandes, complejos y con mayor riesgo de afectar el medio ambiente. 
llegar a la CONAMA o a la COREMA respectiva, según corresponda en el plazo de sesenta días contados desde la publicación. El reglamento de la ley establece las formalidades mínimas que deben cumplir las observaciones. La autoridad administrativa tiene la obligación de ponderar, en los fundamentos de su resolución, las observaciones formuladas y notificar a quienes las hubieren hecho. Consecuentemente, las observaciones que formule la comunidad no son vinculantes para la autoridad, que cumple con solo tenerlas en cuenta al dictar su resolución.

Luego de 10 años de vigencia del SEIA la evaluación corriente de los mecanismos de participación establecidos en la ley es que ellos presentan múltiples limitaciones que los hacen poco efectivos desde el punto de vista de las comunidades afectadas, así como también desde el punto de vista de su legitimidad política. Vale decir, las limitaciones se traducen en que los actores principales involucrados en los conflictos ambientales-empresas, organizaciones ambientalistas, organizaciones comunitarias- tienden a utilizar otros mecanismos que consideran más efectivos que el sistema establecido ${ }^{21}$.

Por una parte, la opción de presentar una Declaración, en vez de un Estudio de Impacto Ambiental, permite prescindir del proceso participativo. Por otra, las observaciones realizadas por la comunidad tienen demasiadas restricciones: no se presentan con anterioridad a que el proyecto esté integrado en el sistema (con lo que se pierde un enorme campo de negociación, relacionado sobre todo a la ubicación física de los proyectos), sólo pueden referirse a materias ambientales (aun cuando los proyectos producen muchos otros efectos), sólo se cuenta con sesenta días para hacerlo (lo que supone una comunidad organizada previamente y que cuenta con la información y competencias técnicas requeridas para ello) y, finalmente, no son vinculantes para la decisión. De manera adicional, las observaciones se refieren solamente al proyecto ingresado al SEIA, pero los proponentes tienen la opción de realizar adendas al proyecto con posterioridad. Ello ha producido la tendencia a presentar proyectos que omiten los aspectos más conflictivos, incorporándolos luego en las adendas, que no pasan por el proceso de participación ciudadana.

También ha sido criticada la ubicación institucional de la CONAMA y la composición de las COREMAS. Básicamente el problema consiste en la pertenencia a un ministerio político, como la Secretaría de la Presidencia, y la falta de autonomía de las instancias regionales con respecto a autoridades sectoriales cuyas prioridades no son la preservación y cuidado del medio ambiente. La discusión ha llevado a la presentación de un proyecto de ley para la creación del Ministerio del Medio Ambiente y la Superintendencia Ambiental, estando pendiente la modificación del SEIA ${ }^{22}$.

El Ministerio de Obras Públicas adaptó el sistema puesto en práctica para los proyectos ingresados al SEIA, aun cuando los proyectos públicos no tenían la obligatoriedad de presentar estudios de impacto ambiental. Para ello creó una unidad dedicada al tema (hoy Secretaría

21 Entrevista a Rodrigo Egaña, ex director de CONAMA, en junio de 2008.

22 Análisis sobre el SEIA y la institucionalidad ambiental en la serie de Documentos En Foco, № 91 al 95, de Expansiva, disponibles en: http://www.expansiva.cl. 
Ejecutiva de Medio Ambiente y Gestión Territorial (SEMAT)) en la Dirección de Obras Públicas. El trabajo desarrollado en obras públicas aborda algunas de las limitaciones del SEIA, pues introduce de modo sistemático la participación anticipada, lo que evita algunos de los principales conflictos relacionados con la ubicación de los proyectos (trazado de los caminos, por ejemplo). También introdujo criterios de participación ciudadana en las Bases de Licitación de obras viales y otras, extendiendo así el alcance institucional de la participación. También desarrolló Manuales, tanto para los proyectos de infraestructura, como para proyectos enfocados al mundo indígena. Los manuales son instrumentos destinados a fortalecer la capacidad de las comunidades para realizar el proceso de participación de manera más informada, consistente y productiva. Como se verá luego, el MOP ha participado junto a MIDEPLAN en la incorporación de los criterios de participación en el Sistema de Inversión Pública, sobre la base de su experiencia previa y el carácter pionero de su trabajo dentro de la administración pública. No existen, sin embargo, evaluaciones disponibles sobre el funcionamiento de estos procesos, en base a estándares de participación que permitieran perfeccionarlos o replicarlos en otras reparticiones.

\section{LA CRISIS DE LA INSTITUCIONALIDAD LOCAL}

Gran parte de los mecanismos de participación existentes, así como de los propuestos, se ejercen en el nivel local, siendo frecuente la afirmación de que es en ese ámbito que esta se puede ejercer de mejor manera. Sin embargo, los estudios existentes sobre la normativa jurídica indican serios problemas y déficit en la institucionalidad existente. Sobre todo en lo referido a la valoración y utilización de los instrumentos por parte de los propios municipios (SUBDERE, 2004). En el cuadro siguiente se resumen las valoraciones de los instrumentos legales existentes: CESCOS, Audiencias, Plebiscitos comunales, Ordenanzas de Participación, según la clasificación de municipios de acuerdo a su capacidad que utiliza la SUBDERE (siendo el tipo 1 la menor capacidad financiera e institucional y el tipo 8 la más alta).

A lo anterior se debe sumar el dato que dice que sólo el 19\% de la población conoce la existencia de los CESCOS (Más Voces, 2005), lo que llevó a la SUBDERE a promover la realización de presupuestos participativos y cartas ciudadanas. Mediante los primeros los municipios están incorporando a la población a la decisión sobre algunas partidas presupuestarias (generalmente pequeñas) y a través de las cartas se establecen compromisos de gestión (y también cogestión) entre municipio y comunidad respecto a temas de interés. Las más interesantes de ellas incluyen mecanismos de control y evaluación de lo comprometido. El programa de presupuestos participativos está en plena ejecución, el de cartas ciudadanas ya se realizó sin que exista evaluación conocida de sus resultados.

\section{LA INNOVACIÓN LOCAL EN BUSCA DE INSTITUCIONALIDAD}

Más allá de los instrumentos establecidos por ley para la participación local, existe una gran cantidad y variedad de formas mediante las cuales diferentes grupos organizados, en conjunto con municipios y organismos públicos sectoriales han desarrollado acciones participativas en distintos ámbitos. Dicha creatividad, sin embargo, no resulta adecuadamente 


\section{CUADRO 4}

Valoración de los instrumentos legales de participación en el ámbito local según tipo de municipio

\begin{tabular}{|l|l|}
\hline TIPO DE MUNICIPIO & \multicolumn{1}{c|}{ VALORACIÓN DE LOS INSTRUMENTOS LEGALES } \\
\hline $\begin{array}{l}\text { Tipos 1,2,3 } \\
\text { (149 municipios) }\end{array}$ & $\begin{array}{l}\text { Baja representatividad de CESCOS } \\
\text { Falta capacitación de funcionarios en gestión participativa } \\
\text { Municipios rurales: cercanía en vez de instrumentos formal } \\
\text { Faltan recursos para plebiscitos } \\
\text { Faltan compromisos e interés ciudadano para participar } \\
\text { Dispersión geográfica y principal preocupación por fuentes laborales } \\
\text { Algunos sistemas alternativos de participación: consejos territoriales, } \\
\text { organizaciones funcionales }\end{array}$ \\
\hline $\begin{array}{l}\text { Tipos 4,5,6 } \\
(166 \text { municipios) }\end{array}$ & $\begin{array}{l}\text { Alto costo de plebiscitos } \\
\text { Falta de interés de las personas por participar en CESCOS } \\
\text { Formas alternativas: talleres territoriales, encuestas }\end{array}$ \\
\hline $\begin{array}{l}\text { Tipos } 7,8 \\
(20 \text { municipios })\end{array}$ & $\begin{array}{l}\text { Cuentan con los } 5 \text { instrumentos legales } \\
\text { Interés de desarrollar metodologías participativas } \\
\text { Instrumentos legales no impactan en la gestión participativa: baja } \\
\text { valoración, alto costo, escaso interés de personas en ellos } \\
\text { Iniciativas adecuadas a la propia realidad comunal }\end{array}$ \\
\hline
\end{tabular}

Fuente: Elaboración propia sobre la base de SUBDERE (2004).

recogida por los instrumentos legales y de política pública que existen. Más bien se trata de innovaciones poco conocidas y producto de la iniciativa local o de la reformulación local de algunos programas públicos, pero que no se generaliza más allá de algunas comunas.

Una muestra de innovaciones locales la constituyen las iniciativas presentadas al Premio Innovación y Ciudadanía en sus cinco versiones desde el año 2000 en adelante, provenientes tanto de la sociedad civil como del Estado (en proporciones similares), que muestran la existencia de un conjunto vasto y diverso de iniciativas que vinculan proactivamente a la sociedad civil y al Estado, principalmente en el ámbito subnacional.

Las innovaciones que provienen del sector público son normalmente procesos relativamente recientes, que surgen desde agencias específicas y no de las líneas centrales de la política, por lo que su camino de institucionalización es aún incierto. En el caso de los programas más institucionalizados percibimos más bien una concepción de "participación" que de consagración y ejercicio de derechos ciudadanos, como es particularmente el caso de las experiencias de salud (aunque ello ha comenzado a cambiar) y gran parte de las iniciativas 


\section{CUADRO 5}

Premio a la innovación en ciudadanía.

Postulaciones por tipo de institución

\begin{tabular}{|l|c|c|c|c|c|c|c|}
\hline INSTITUCIÓN /AÑO & 2000 & 2001 & 2002 & 2004 & 2006 & TOTAL & $\%$ \\
\hline Estado & 280 & 203 & 147 & 197 & 129 & 956 & 51,6 \\
\hline Sociedad civil & 192 & 173 & 202 & 182 & 121 & 870 & 46,9 \\
\hline Mixtas & - & - & - & - & 29 & 29 & 1,5 \\
\hline Total & 472 & 376 & 349 & 379 & 279 & 1.855 & 100,0 \\
\hline
\end{tabular}

Fuente: Delamaza y Fernández (2008: 20).

municipales. Está más extendida la idea de innovación asociada a los cambios en los estilos de gestión, que a la introducción de prácticas radicalmente nuevas orientadas al fortalecimiento de la ciudadanía social ${ }^{23}$.

Más allá del "primer impacto" de las innovaciones se observa la falta de mecanismos de aprendizaje y acumulación de conocimiento en el sector público. Son experiencias aún precarias, que dependen del apoyo político del alcalde, la disponibilidad de recursos financieros, el apoyo del nivel central, etc. La dificultad para producir cambio institucional a partir de la innovación exitosa es un rasgo altamente negativo en las políticas públicas. No parece haber instrumentos que les permitan una evaluación del impacto real de las acciones y en función de ella organizar la replicabilidad, transferencia o modificación de lo realizado. Todavía parece ser más determinante la estructura sectorial de las decisiones programáticas y el control político de los recursos institucionales.

Los principales asuntos pendientes en estas innovaciones son el control ciudadano y la deliberación. La incorporación de un enfoque de "ciudadanía deliberante" en la gestión pública debe distinguirse claramente del acceso a la información, la participación en la ejecución de programas y las consultas a la gente. Pareciera ser que la facultad de deliberar con consecuencias vinculantes para la política pública está restringida a autoridades, técnicos y "poderes fácticos", pero tiende a dejar fuera a las expresiones propias de la ciudadanía 24 .

23 Debe considerarse que también hay iniciativas de la sociedad civil que surgieron de programas públicos o de cooperación entre ambos sectores. "Ubicar el asunto de la acción colectiva a nivel local como un problema de ciudadanos contra gobiernos o a pesar de los gobiernos o más allá de los gobiernos, es perder de vista el hecho de que muchas historias exitosas de la acción colectiva son fundamentadas sobre interacciones fuertes entre las instituciones sociales y públicas, tanto a nivel local como nacional" (Berdegué, 2000: 12).

24 En Chile no hay Consejos Locales en torno a las áreas de acción comunal (como los que existen en Brasil, Bolivia o Colombia); los CESCOS sólo tienen facultades consultivas y no funcionan casi en ningún lugar; y las experiencias de presupuesto participativo aún no se generalizan; entre otras falencias. 
Las experiencias innovadoras están transformando las figuras típicas de la organización social e institucional, de acuerdo al escenario de transformaciones en el que los actores están moviéndose. Lo que surge no responde a modelos puros, sino a una suerte de mestizaje en varios planos: entre los niveles de la acción, entre los tipos de instituciones, en los mecanismos de representación, en las identidades de cada uno. A su vez la innovación supone una cierta continuidad de la acción durante un tiempo. Es un problema para los programas así llamados innovadores: trabajan con plazos muy breves y metas muy acotadas y específicas. El problema no es sólo de la continuidad política en sí misma, sino también el origen de los cambios y el poder relativo de las agencias que pueden construir gobernabilidad "desde abajo". Las decisiones de interrumpir un programa o bien provienen de una decisión de política general, originada en La Moneda, o bien a partir del control de los recursos y creciente orientación programática del Ministerio de Hacienda ${ }^{25}$.

En general las iniciativas innovadoras se proyectan cuando involucran una acción reflexiva sobre sí mismas. Pueden ser pequeñas comunidades que a través de un proceso participativo se han planteado "hacia donde quieren ir", en una lógica de acción proyectiva. Se registran resultados interesantes en términos de orientar la inversión de agencias sectoriales, movilizar a la comunidad y sus propios recursos, generar planificaciones plurianuales, etc. La proyección y scaling up de esas experiencias depende directamente de avances sostenidos en el proceso de descentralización, del apoyo que reciban desde los niveles superiores de la acción pública y de la mantención de su autonomía de decisiones. Es en ese plano donde se verifican hasta ahora los mayores problemas para la incorporación de la participación en el sistema público ${ }^{26}$.

\section{AVANCES SECTORIALES Y REGIONALES}

En este último acápite consignaremos avances que se han venido realizando en diferentes ámbitos y que resultan ejemplos interesantes de tomar en cuenta para la formulación de un nuevo ciclo de reformas tendientes a fortalecer la participación ciudadana en políticas públicas.

El Ministerio de Salud asumió la incorporación de la participación ciudadana como parte del proceso de modernización de la gestión pública, apuntando a la democratización y descentralización en la entrega de su servicio. Los objetivos fueron coordinar las acciones de los equipos técnicos con la ciudadanía con el propósito de influir en la mejora de la salud, calidad de vida y la calidad del servicio. Estos objetivos surgen en relación a la

25 De hecho el Programa de Evaluación de Programas Gubernamentales no depende de MIDEPLAN, sino de la Dirección de Presupuesto, organismo del Ministerio de Hacienda, lo que significa que esta repartición negocia tanto las orientaciones como el financiamiento de los programas sectoriales, los que luego evalúa según sus propios criterios, sin atenerse ni a los planes sectoriales ni a metas de gestión social más amplias. Sobre este "modelo presupuesto" de gestión pública y sus diferencias con el "modelo plan", ver CLAD/BID (2007: 11-12).

26 Un contraejemplo de continuidad es Bogotá, donde a través de cuatro administraciones de diferentes tendencias se ha perfeccionado un sistema de planeación participativa como parte de un diseño de gobernabilidad democrática (Velásquez y González, 2003). 
implementación de un nuevo tipo de gestión plasmado por la Reforma de Salud, la cual orienta principalmente a la prestación de servicios públicos y privados, con el fin de incorporar la noción de derechos universales a partir de la cual "define políticas de acceso, oportunidad y financiamiento". Por otro lado, esta propuesta intenta promover la gestación y consolidación de redes de salud estableciendo "estándares nacionales de calidad" (Fernández y Ochsenius, 2006) ${ }^{27}$.

En el ámbito territorial destacan las experiencias de planificación. Si bien es cierto que en el ámbito municipal se establece que la formulación de los Planes de Desarrollo Local (PLADECO) debe asegurar la participación de la comunidad, la práctica corriente es que ésta consista en talleres consultivos organizados por consultoras externas, donde se recogen opiniones de quienes asisten. Pero no están definidos estándares que esa participación debe cumplir (ni por parte de la Subsecretaría de Desarrollo Regional (SUBDERE) que ha normado la elaboración de los PLADECO, ni por parte de los propios municipios que los encargan), ni está definido el modo de incorporación de los resultados de dicha participación en el propio plan. Sin embargo, lo que limita más severamente el alcance y relevancia de la participación en los PLADECO es el hecho de que no existan instancias evaluativas y de control de gestión y ejecución del plan, ni que se puedan impugnar decisiones o acciones que no resultan consistentes con el plan elaborado. Por último, la modalidad ocasional que asume la participación en los PLADECO hace que no se produzca un proceso en la ciudadanía, sino que la opinión de los dirigentes se utilice apenas como un insumo en la elaboración del plan (Montecinos, 2007).

Desde el 2007 la SUBDERE está desarrollando un programa de trabajo de fomento de la participación ciudadana orientado a que ciudadanos puedan influir en las decisiones de las políticas públicas a nivel regional y local, generando instancias de participación vinculante para mejorar la eficiencia y la eficacia de éstas. Los principios asociados a esta estrategia son los denominados mínimos universales, orientados principalmente a mecanismos de información, reclamos y sugerencias, y los máximos, los cuales son instancias pilotos asociadas al control social y a la rendición de cuentas (cartas ciudadanas, presupuestos participativos). Las iniciativas concretas son el Programa de Apoyo a los Presupuestos Participativos, los acuerdos con Gobiernos Regionales para la implementación de Planes Regionales de Participación Ciudadana y la actualización de las Estrategias de Desarrollo Regional con enfoque participativo.

En el ámbito regional durante los años 2005 y 2006 se realizaron interesantes ejercicios de planificación regional. Una de las experiencias piloto implementadas es el Proceso de Discusión Presupuestaria Territorial en la Región del Bío-Bío, la cual tiene como objetivo coordinar a los diversos actores (públicos, privados y sociedad civil), promoviendo la participación ciudadana local, a través de todos sus niveles de decisión (diagnóstico, discusión,

27 El proceso del sector salud ha pasado por varias etapas y programas diferentes, mayoritariamente orientados según una modalidad instrumental, pero crecientemente vinculado a las metas de ciudadanía "neo-universalista" que plantea la Reforma de Salud y el Sistema de Garantías Explícitas (Fernández y Ochsenius, 2006). 
decisión y control). Los criterios con los que se implementa esta iniciativa son la participación, organización (a nivel comunal o territorial) y su continuidad en el tiempo, teniendo siempre como finalidad la profundización del Modelo de Gestión Pública Territorial.

Las fortalezas que se mencionan dentro del desarrollo de este proceso es la posibilidad de generar compromisos de inversión verificables, la cual se transforma en precedente para asentar un cambio cultural en relación a la participación de diversos actores en la formulación y desarrollo de las políticas públicas, con el propósito de legitimar un modelo de planificación territorial con base ciudadana. A partir de la evaluación realizada se señala que el éxito o fracaso en la implementación tiene relación con las particularidades territoriales, y las bases asentadas para que se instale un proceso de gestión participativa. Además de la comprensión que éste es un proceso de largo plazo, que no sólo debe tener en cuenta las capacidades participativas de la ciudadanía, sino además de las autoridades e instituciones convocadas a participar. ${ }^{28}$

Otro avance sectorial es el de incorporación de la participación ciudadana en el Sistema Nacional de Inversiones, como iniciativa de MIDEPLAN incluyéndola como una iniciativa integrada a los requisitos de admisibilidad de proyectos, seleccionando programas piloto donde se incorpora el requerimiento en sus etapas de diseño y de ejecución. El propósito de esta iniciativa es sumar a los diferentes sectores de forma gradual y paulatina, con el objetivo de que en el año 2010 la participación ciudadana sea exigida dentro de todas las iniciativas de inversión. Considerando dentro de esta propuesta la importancia de generar un proceso regulado que aclare a la ciudadanía la forma en que se implementarán los procesos participativos en cada uno de los sectores, de modo que las demandas de éstos sean consideradas tanto para la mejora de los proyectos como para otorgar una mayor legitimidad pública a éstos. Dentro del proceso presupuestario 2008, considerado como año piloto, se estableció un análisis del cumplimento de los requerimientos anteriormente señalados, pero sin emitir juicios con respecto a si los procesos participativos son o no pertinentes, o si se acogen pertinentemente las iniciativas de la ciudadanía vinculada. Para el año presupuestario 2009 estas exigencias debieran ampliarse a otras iniciativas dentro de las que se incluyen diversos sectores, especialmente proyectos del MOP29.

Una última experiencia, de gran importancia por las proyecciones que puede tener y la solidez del proceso previo es la constitución de la Mesa Regional de Desarrollo Rural de la Región de Coquimbo. La Mesa se constituyó en marzo de 2008, como resultado de un proceso de más de dos años de demanda campesina y negociaciones entre diversas instituciones de la región. Tiene como contexto el Instituto de Desarrollo Agropecuario (INDAP), la Asociación de Municipalidades Rurales del Norte Chico, el Gobierno Regional (la Mesa la preside el Intendente Regional) y el conjunto de organizaciones campesinas de la Región de Coquimbo. Es una experiencia de modernización institucional de los órganos de

28 En 2008 y 2009 el Sistema de Gestión del Conocimiento sobre Desarrollo de los Territorios-Territorio Chile, seleccionó 20 destacadas en la materia, la mayor parte de las cuales tienen componentes de participación ciudadana. Ver al respecto: http://www.territoriochile.cl.

29 http://sni.mideplan.cl/. 
Gobierno y municipalidades, y de desarrollo de la capacidad organizativa de los campesinos para incidir en la construcción de políticas regionales de desarrollo rural, que se manifiesta en un acuerdo entre las partes para instalar una institucionalidad cuya misión es elaborar y ejecutar un Plan de Desarrollo, con la concurrencia de una amplia gama de entidades públicas y de la sociedad civil (Ríos, 2008).

Lo más relevante del proceso de la Mesa Rural es la construcción de capacidades organizativas de los campesinos, que elaboran sus propias definiciones de desarrollo, estructuran un discurso inclusivo y despliegan una estrategia de posicionamiento en el ámbito político que es compartida por los municipios rurales. Todo esto en el marco de los espacios de acción que se generaron con la implementación de los Consejos de Desarrollo Local (CDL), instrumento de concertación entre el Estado y la sociedad civil que crea el INDAP para dar viabilidad al "Proyecto de Desarrollo Rural de Comunidades Campesinas y Pequeños Productores Agropecuarios (PRODECOP)", de modernización de la agricultura campesina. El caso de la Mesa Regional se diferencia de las múltiples Mesas Territoriales que se han implementado para abordar diferentes temáticas en su grado de institucionalización y formalización, en el alcance de sus objetivos y en la amplitud de la representación que incluye. De hecho en Coquimbo existían una decena de Mesas relativas a temas que ahora están incluidos y articulados en esta instancia, por lo cual han sido desactivadas ${ }^{30}$.

\section{CONCLUSIONES SOBRE EL DISEÑO INSTITUCIONAL DE LA PARTICIPACIÓN CIUDADANA}

La revisión de la trayectoria política, iniciativas legales, institucionalidad, funcionamiento de la normativa existente e iniciativas sectoriales y regionales muestra un panorama amplio y dinámico de las formas de institucionalización de la participación en las políticas públicas en Chile. Sin embargo, este panorama presenta un conjunto de limitaciones, producto de su énfasis principalmente consultivo, su escaso soporte jurídico y técnico y su carácter instrumental. Estos rasgos comunes obedecen a patrones de orientación política que han restringido la participación en el país, relacionados con el modelo de gobernabilidad que ha orientado la construcción y gestión estatal durante estos años. Esa imbricación entre diseños de participación y política es la que el caso chileno pone de relieve.

El enfoque de construcción democrática vincula la consideración de los aspectos institucionales con los desarrollos de la actoría social, dada la estrecha imbricación entre actores situados en distintos niveles de poder y ámbitos de interés público. Vale decir, que los cambios institucionales que redundan en "apertura" del Estado a la sociedad facilitan el surgimiento de una ciudadanía "activa" y "deliberante". De este modo, el rol del Estado no

30 Existen algunas instancias que han alcanzado un grado interesante de institucionalización en el ámbito regional, como la Comisión Regional de la Pesca Artesanal de Maule (COREDEPA) y el consorcio Araucanía Andina (Programa Ciudadanía y Gestión Pública, 2006). Pero la experiencia más extendida es de instancias ad hoc, sin criterios claros de integración y cuya sostenibilidad es baja, pues está asociada a determinadas orientaciones de la autoridad. Las mesas generadas por el Programa Chile Emprende en diferentes territorios podrían dar lugar a formas nuevas de institucionalización si resuelven esas limitaciones (Gómez et al., 2006). 
culmina con el reconocimiento legal de ciertos derechos de ciudadanía ("pasiva") sino que puede ir más allá. Es ahí donde se abre el espacio de la participación, que puede involucrar la definición de intereses, prioridades y control del quehacer público, incidir en la toma de decisiones, deliberar argumentativamente y ampliar los temas de la agenda política y coordinar sus esfuerzos para la generación y ampliación de bienes públicos. El supuesto es que esa provisión de bienes públicos no está asegurada por sí sola a través de los recursos estatales ni de la operación del mercado.

Sin embargo, la construcción de interfaces entre Estado y sociedad abarca un amplio rango de materias y modalidades y sólo algunas de ellas pueden considerarse participación ciudadana con consecuencias democratizantes, de acuerdo al planteamiento que hemos esbozado: las que denotan un proceso de apertura efectivo y ampliación democrática del Estado de efectos duraderos; las que colaboran a superar la fragmentación de los actores de la sociedad civil y a generar en ella nuevas capacidades para la incidencia en la esfera pública; las que promueven el cambio institucional en favor de un "empoderamiento" de la sociedad en los asuntos públicos. El Estado cuenta con recursos específicos para promover o inhibir estos procesos, a saber el uso monopólico de la fuerza, la obligatoriedad de la norma legal y la legitimidad democrática. Vale decir, la capacidad de moldear los espacios y relaciones que establece, es alta. De allí que sea relevante analizar tanto las orientaciones de política como los diseños institucionales que el Estado pone en práctica para la participación de la ciudadanía y el vínculo con la sociedad. De ello dependerá, en gran medida, el potencial y los límites de la participación.

El artículo analizó diversas iniciativas y orientaciones presentes en el Estado chileno, evaluando algunas de sus potencialidades. La diversidad de agendas que vinculan al Estado con la sociedad a través de las políticas públicas relevan la importancia y amplitud de este vínculo para la acción estatal. Sin embargo, los resultados indican un desempeño modesto del Estado chileno en cuanto a institucionalizar adecuadamente la participación de las y los ciudadanos, convirtiendo esa participación en un factor de construcción y fortalecimiento democrático. En las diferentes dimensiones de análisis revisadas, los resultados son extremadamente limitados y los desafíos de gran envergadura.

Las formas de participación utilizadas tienen mayoritariamente un carácter institucionalizado y se ejercen más bien en las etapas de implementación que en la definición de las agendas. Su énfasis está en el espacio microlocal -el barrio, la comunidad rural-y se refiere a modalidades de cofinanciamiento, de favorecer pequeñas iniciativas de desarrollo local o adecuar parcialmente los instrumentos de inversión pública en pequeña escala. Estas modalidades han dado origen a un importante número de innovaciones locales donde convergen los actores de lo público, generalmente autoridades locales u operadores de los servicios sectoriales con dirigentes sociales. Muchas de las iniciativas innovadoras muestran un cierto potencial de fortalecimiento ciudadano -más que capacidad de modificación institucional del Estado- pero lo hacen a través de unidades específicas y aisladas entre sí. Se multiplican allí donde existen contrapartes sociales organizadas previamente y agentes públicos con voluntad política de apertura, pero sin responder a lineamientos comunes desde el Estado central. 
Dos rasgos propios de la institucionalidad estatal acrecientan las limitaciones de la agenda participativa: el centralismo y el predominio excesivo del Ministerio de Hacienda en la determinación de metas de la acción pública. El sistema político chileno es altamente centralizado y el diseño de gobernabilidad vigente en los últimos veinte años tiende a profundizar dicho rasgo, pues el proyecto político de la transición contempló solamente la democratización política de los municipios y no un cambio de la arquitectura institucional y administrativa del país. Por su parte, el énfasis en la responsabilidad fiscal ha fortalecido significativamente el rol del Ministerio de Hacienda, no sólo en el control del gasto, sino en la orientación del conjunto de los programas, labor que realiza a través de diferentes instrumentos de modernización y evaluación de programas públicos. Ese rol domina la gestión del Estado, pues no tiene interlocutores para negociar metas específicas, ni mecanismos para acoger políticas concertadas con la sociedad civil en espacios regionales o locales. Fomenta modalidades de cofinanciamiento que alivien el gasto fiscal, pero no instancias de decisión conjunta o coprovisión de servicios sobre la base de agendas compartidas y adecuación de instrumentos de inversión y acción pública. La llamada "agenda de modernización del Estado" promueve a su vez procesos inspirados en los mismos principios -asegurar la eficacia y eficiencia de la gestión en su conjunto- y no contempla adecuaciones como las que requiere la participación y concertación con la sociedad civil.

De acuerdo a lo expuesto, se puede concluir que el proceso de participación ocupa un espacio institucional reducido y con baja articulación al ciclo de las políticas públicas en las que interviene. Esto debilita su potencial, por cuanto limita sus posibilidades de incremento de escala.

En síntesis, los espacios y mecanismos de participación están incrustados (embedded) en una trama institucional más amplia. Sus posibilidades, de avance, sustentabilidad, apropiación ciudadana, incremento de impacto (scaling up) y capacidad transformadora están en directa relación con la coherencia y articulación interna de los diseños institucionales de la gestión pública. En la medida que el proceso de participación no forma parte estructurante del proceso democrático ni de la toma de decisiones en la gestión estatal, su potencialidad se ve naturalmente disminuida ${ }^{31}$.

La problemática de los diseños institucionales de la participación no es tanto la de crear instancias acordes a un modelo preestablecido, sino la de generar dinámicas continuas de democratización en los ámbitos donde se aplica, de tal modo de aumentar la incidencia relativa de los sectores tradicionalmente excluidos, así como de introducir instancias de transparencia y control públicos para los mecanismos de asignación de bienes y servicios públicos. La publificación de las relaciones entre el Estado y el ciudadano representa una aspiración y un norte que actúa en contra de orientaciones tradicionales como el clientelismo

31 La adscripción de algunos convenios y tratados internacionales, así como la emergencia del neouniversalismo en diversas áreas de la política social, introduce innovaciones que podrían evolucionar hacia el diseño institucional de modalidades de participación sujetas a estándares más altos y mayor publificación. 
y el corporativismo, así como expresas tensiones con la agenda de modernización neoliberal del Estado, que conceptualiza al ciudadano como cliente.

\section{BIBLIOGRAFÍA}

Aguilera, Carolina (2009): "Un análisis de las comisiones asesoras presidenciales del Gobierno de Bachelet", Documento de Trabajo, Programa de Gobernabilidad, FLACSO-Chile, Santiago.

Avritzer, Leonardo (2002): Democracy and the Public Space in Latin America, Princeton University Press.

Bebbington, Anthony, Gonzalo Delamaza y Rodrigo Villar (2005): El desarrollo de base y los espacios públicos de concertación local en América Latina. Disponible en: http://www.innovacionciudadana. cl/portal/despliegue.php?ID_SECCION=1\&ID_CONTENIDO=14.

Berdegué, Julio (2000): Cooperando para competir. Factores de éxito de las empresas asociativas campesinas, Red Internacional de Metodologías de Investigación, mimeo.

BID (2006): La política de las políticas públicas, BID/DRCLAS, Washington.

Canto, Manuel (2005): Las políticas públicas participativas, las organizaciones de base y la construcción de espacios públicos de concertación local. Disponible en: http://www.innovacionciudadana. $\mathrm{cl} /$ portal/imagen/File/canto.pdf.

Boeninger, Edgardo (2007): Políticas públicas en democracia. Institucionalidad y experiencia chilena 1990-2006, Uqbar, Santiago.

CLAD/BID (2007): Modelo abierto de gestión para resultados en el sector público, CLAD/BID, Caracas.

Comité Interministerial de Modernización de la Gestión Pública (2000): El Estado al Servicio de la Gente. Balance 1994-2000, Santiago.

Consorcio para la Reforma del Estado (2009): Un Estado de clase mundial al servicio de las personas, Consorcio para la Reforma del Estado, Santiago.

Cunill, Nuria (2007): "Políticas públicas y participación ciudadana en América Latina", Conferencia Inaugural Seminario Internacional Participación Ciudadana en las Políticas Públicas, Santiago, octubre 18 y 19 de 2007.

Delamaza, Gonzalo (2005): Tan lejos tan cerca. Políticas públicas y sociedad civil en Chile, LOM Ediciones, Santiago.

(2006): "Los ciudadanos ¿podemos gobernar(nos)?”, Asuntos Públicos, № 555. Disponible en: http://www.asuntospublicos.cl/detalle.php?id=3426.

(2009): "Fortalecimiento de la sociedad civil para la acción pública y la gobernanza democrática en contextos de desarrollo", Documento de Trabajo, № 10, Centro de Estudios de Cooperación al Desarrollo, Ediciones del Instituto Universitario de Estudios Europeos, Madrid. Disponible en: http://www.cecod-fi.net/uploads/DocuWeb\%20Doc.\%2010\%20 Delamaza.pdf.

Delamaza, Gonzalo y Margarita Fernández (2008): “¿Por qué premiar la gestión pública innovadora con enfoque ciudadano?", en Programa Ciudadanía y Gestión Pública: Premio Innovación y Ciudadanía. 20 experiencias destacadas 2006, Universidad de Los Lagos, Santiago, pp. 5-20. 
DOS (2007): Agenda Pro Participación, DOS, Santiago.

Fernández, Margarita y Carlos Ochsenius (2006): Contribuciones a la Reforma de Salud, Programa Ciudadanía y Gestión Pública, Universidad de Los Lagos, Santiago.

Fernández, Matías y Martín Ordóñez (2007): Participación ciudadana en la agenda gubernamental de 2007. Caracterización de los compromisos, Programa Ciudadanía y Gestión Pública. Disponible en: http://www.innovacionciudadana.cl/portal/imagen/File/barometro/Informe\%20final\%20 S.E..pdf.

Font, Joan (2004): “Participación ciudadana y decisiones públicas: conceptos, experiencias y metodologías", en Alicia Ziccardi (comp.): Participación ciudadana y políticas sociales en el ámbito local, Instituto de Investigaciones Sociales de la Universidad Nacional Autónoma de México, México, pp. 23-41.

Font, Joan, Ismael Blanco, Ricard Gomà y Marina Jarque (2000): "Mecanismos de participación ciudadana en la toma de decisiones locales: una visión panorámica", Concurso de Ensayos del CLAD, Caracas. Disponible en: http://www.clad.ve.org.

Gerber, Mónica (2007): ¿Cuánto sabemos de participación ciudadana?. Disponible en: http://www. innovacionciudadana.cl/portal/imagen/File/barometro/segundo_informe_barometro_de_ la_ciudadania.pdf.

Gómez, Francisco (ed.) (2006): Gestión público privada del desarrollo territorial y empleo, Instituto de Desarrollo Regional IDER, Santiago.

Grompone, Romeo (ed.) (2007): La Participación desplegada en la política y la sociedad: temas olvidados, nuevos enfoques, Universidad Católica del Perú, Lima.

Hevia, Felipe (2005): “Institucionalização da participação cidadã: análise dos marcos legais da participação na América Latina", en Evelina Dagnino, Aldo Panfichi y Alberto Olvera (orgs.): A disputa pela construção democrática na América Latina, Paz e Terra, Sao Paulo.

(2007): La iniciativa legislativa popular en América Latina, Fundación Chile XXI, Santiago.

López, Juan y Paula Pacheco (2006): "Participación ciudadana y calidad de las políticas sociales", en Serie en Foco, № 88, Expansiva, Santiago. Disponible en: http://www.expansiva.cl/media/ en_foco/documentos/23082006113005.pdf.

Márquez, Francisca (2001): "Participación ciudadana en la gestión pública”, en Temas Sociales, Ediciones SUR, Vol. 41, Santiago, octubre. Disponible en: http://www.sitiosur.cl/r.php?id=84.

Más Voces (2005): Más democracia. Propuestas para la participación ciudadana, Más Voces, Santiago.

Montecinos, Egon (2007): “Los límites de la modernización municipal para profundizar la participación ciudadana en Chile ¿Es la gobernanza de proximidad una alternativa?", Gestión y Política Pública, segundo semestre, Vol. XVI, Nº 002, México, pp. 319-351.

Nun, José (2002): Democracia. ¿Gobierno del pueblo o gobierno de los políticos?, Fondo de Cultura Económica, México.

O’Donnell, Guillermo (1993): "Delegative Democracy?", Journal of Democracy, Vol. 5, № 1.

Payne, Mark (coord.) (2003): La política importa. Democracia y desarrollo en América Latina, BID/ IDEA, Washington DC. 
Programa Ciudadanía y Gestión Pública (2006): Nuevas experiencias de gestión pública ciudadana, Universidad de Los Lagos, Santiago.

PNUD (2004): La democracia en América Latina. Hacia una democracia de ciudadanas y ciudadanos, PNUD, Buenos Aires.

Recabarren, Lorena y Marcel Aubry (2005): “Resultados del Estudio de Asociatividad y Participación Ciudadana", en VV.AA: Más Democracia. Propuestas para la participación ciudadana, Más Voces, Santiago.

Remy, María Isabel (2005): ¿Qué ha pasado con la participación ciudadana en Perú?, Instituto de Estudios Peruanos, Lima.

Ríos, Sergio (2008): Consejo de Desarrollo Local (CDL): una experiencia de participación campesina en la Región de Coquimbo Chile, Encuentro Innovación Local en América Latina, Centro de Investigación y Docencia Económicas A.C. (CIDE).

Salazar, Gabriel y Julio Pinto (2000): Historia contemporánea de Chile I. Estado, legitimidad, ciudadanía, LOM Ediciones, Santiago.

Silva, Patricio (2006): "Los tecnócratas y la política en Chile. Pasado y presente", Revista de Ciencia Política, 26 (2), pp. 175-190.

SUBDERE (2004): Valoración de los mecanismos de participación ciudadana en el ámbito municipal, SUBDERE, Santiago.

Valenzuela, Jaime, Marcelo Reyes, Renán Retamal y Catalina Sánchez (2000): El Programa de Pavimentación Participativa. Disponible en: http://www.uncrdlac.org/SHE/13_6_pavimentacion_participativa. pdf.

Velásquez, Fabio y Esperanza González (2003): ¿Qué ha pasado con la participación ciudadana en Colombia?, Fundación Corona, Bogotá.

Viveros, Felipe (2008): Marco jurídico de la participación ciudadana en Chile, Informe preparado para el Estudio sobre Mecanismos de Participación Ciudadana en el Diseño, Implementación y Evaluación de Políticas Públicas, Inédito. 